\title{
Capabilities and gender: a sum or system of inequalities? The case of Chile
}

\author{
Virginia Guzmán, Emmanuelle Barozet, Eduardo Candia, \\ Bernardita Ibnen and Bettina Leiva
}

ABSTRACT

Setting out from the broad capability approach put forward by Amartya Sen and working with data from the 2009 National Social Stratification Survey (enes), this article explores the influence of sex on differences in the personal capabilities deemed important for attaining outcomes that determine people's levels of well-being or deprivation. In terms of capabilities, it investigates individuals' ability to exercise material, cultural, social and political control over their lives and surroundings, distinguishing between the situation of men and women. Following the construction of individual capability measures, the hypothesis of female disadvantage was tested by the adjustment of multivariate models incorporating relevant controls. The findings suggest that there are non-negligible differences in capabilities between women and men in Chile.

KEYWORDS

JEL CLASSIFICATION

AUTHORS
Human development, gender research, women, capability development, gender equality, measurement, social surveys, statistical methodology, Chile

D63, J16

Virginia Guzmán is a researcher with the Women’s Studies Centre. vbeatrizguzman@yahoo.com

Emmanuelle Barozet is an associate professor at the Department of Sociology of the University of Chile. ebarozet@uchile.cl

Eduardo Candia is an associate researcher with the Desigualdades project. ecandia@uc.cl

Bernardita Ihnen is a sociology student at the University of Chile and intern with the Desigualdades project. berni.ihnen@gmail.com

Bettina Leiva is an economics student at the University of Santiago, Chile and intern with the Desigualdades project. bettinaleivabianchi@gmail.com 


\section{I}

\section{Introduction}

The existence of inequalities ${ }^{1}$ between men and women to the detriment of the latter, and the factors influencing the gender inequality observable in different fields, have been demonstrated by a large body of research carried out since the 1970s by research centres, universities and international organizations. In Chile, this work has been done by State bodies that have included the Women's Studies Centre (CEM), the National Women's Service (SERNAM) and the Research Department of the Labour Inspectorate, while the Gender Affairs Division of the Economic Commission for Latin America and the Caribbean (ECLAC) and the United Nations Development Programme (UNDP) have studied the issue at the Latin American level. ${ }^{2}$ The purpose of this article is to go a step further and analyse the consequences of gender inequalities for the development of individual capabilities and functionings that are part of what determine people's autonomy in making choices about their individual and social well-being.

To this end, the article will set out from the concepts of capabilities and functionings developed by

$\square$ This article has been written within the framework of the Anillo soc12 project, which forms part of the Desigualdades project (www. desigualdades.cl) and is financed by the National Commission for Scientific and Technological Research (CONICYT). The authors are grateful for the comments of Vicente Espinoza, Soledad Herrera, Javier Núñez and a cepal Review referee.

1 "A social inequality is the result of an unequal distribution, in the mathematical sense of the expression, of a society's resources among its members" (Bihr and Pfefferkorn, 2008, p. 9). The term "social inequality" obviously requires considerable clarification in respect of the type of variables that will be considered in defining the different aspects of this inequality. These dimensions may be treated separately or in combination.

${ }^{2}$ For an exposition of these subjects, there is a large literature dealing with the different spheres of inequality, such as economic participation (Contreras, Puentes and Bravo, 2005; Contreras and Plaza, 2010), education (Larrañaga, 2001; Contreras, 2004; Guerrero, Provoste and Valdés, 2006a and 2006b; MINEDUC, 2007), horizontal and vertical segregation in the labour market (Todaro and Yánez, 2004; Acosta, Perticará and Ramos, 2005), employment quality (Leiva, 2000; Acosta, Perticará and Ramos, 2005), incomes (Le Foulon and Beyer, 2002; Berstein and Tokman, 2005; Perticará and Bueno, 2009), career characteristics (Guzmán and Mauro, 2004), access to pensions (Bertranou and Arenas, 2003; Bertranou, 2005), the distribution of time between productive and reproductive work (Todaro and Yánez, 2004; Dussaillant, 2009), social participation (Osborne, 2005; Lombardo, 2008; UNDP, 2010) and political participation and representation (Valdés, 2000; Altman, 2004; Ríos, 2008; UNDP, 2010).
Amartya Sen (1985), which serve not only to consider a hypothetically equitable distribution of goods in a given society, but also to progress towards a better understanding of differences between individuals when it comes to exercising the freedom to be and to act, and to secure access to available goods. Thus, Sen moves away from the abstract universalism of the "subject" to study concrete, historically situated individuals, in this case women and men whose access to goods is differentiated by their position within social relationships in the different spheres of society. The earlier work done in the studies of Nancy Fraser (1985 and 1989) and Fraser and others (1994) on the dimensions of gender injustice also provides a way past the conception of inequalities as originating only in the distribution of goods, without considering other dimensions that are present in the generation of inequalities in social recognition associated with status hierarchies and parity of participation in social and political decision-making.

The aim for Chile, then, is to construct four capabilities - material capability, cultural capability, social capability and political capability - that will be taken as a reference framework for comparing the individual measurements of men and women. From the data processing point of view, use was made of regression models that served to reveal differences in capabilities between men and women, controlling for the effect of relevant sociodemographic variables and other capabilities. To measure capabilities in the case of Chile, the study uses primary data from the National Social Stratification Survey (ENES) of the Anillos soc 12 project. $^{3}$ This survey has unquestionable advantages because of its national

\footnotetext{
3 The reflections set forth in this article form part of a larger field of research into equalities and inequalities in Chile conducted by a multidisciplinary and multi-institutional team whose goal is to carry out comparative study and measurement of emerging trends in social stratification in Chile (www.desigualdades.cl). This programme of research examines the varied dimensions of inequalities, not only those deriving from traditionally recognized dimensions such as occupation, income and education level, but also those relating to social recognition and the involvement of individuals and groups in collective issues and decision-making. Also broached is the sociohistorically constructed character of inequalities that place individuals and groups in differentiated power positions in the different systems of social relations structuring society, which include class, gender, ethnic, spatial and generational systems.
} 
and regional coverage and representativeness, because it is applied individually to men and women while at the same time recording the households they belong to, and because it includes what are emerging variables in the study of social stratification relating to social, cultural, cognitive and political capital.

Two hypotheses are put forward in this paper: (i) women have fewer capabilities than men on average, even when relevant predictors of capabilities are controlled for, and (ii) in determining capabilities, the sex variable interacts with other explanatory variables that affect without nullifying its influence on the differences in capabilities identified between men and women.

\section{II}

\section{Background}

\section{A social gender system}

Gender theory posits the existence of a social system based on the regular reproduction, with greater or lesser alterations, of recurrent patterns that organize relations between men and women at the symbolic, normative and practical level in different social and institutional settings. The gender system is characterized by great temporal and spatial reach, as it encompasses all interactions between men and women in the family, the market, politics and culture, and by its origins in the very constitution of modern societies (Valcárcel, 1991; Astelarra, 2003). Because it encompasses almost all social spaces, and because of its wide time horizon, the social gender system has a great capacity to affect other social systems, and can also be influenced by them. From a socio-historical perspective, the social gender system, as it is now known, has its roots in the beginnings of modern societies: it can be seen in the radical separation of the sexes in the hegemonic discourses of the imaginary institution of modernity, in the sexual division of labour, in gender hierarchies, in the private-public dichotomy, and in the inclusion and exclusion criteria of the structure of rights that regulate citizens.

In this context, the thinking about "gender justice" developed by Fraser (1985 and 1989) and Fraser and others (1994) distinguishes different dimensions that are fairly independent of one another: the economic dimension of redistribution, the cultural dimension of recognition and the political dimension of representation, which they integrate into the more general idea of
This article is structured as follows. Section II reviews the capabilities approach as proposed by Sen, emphasizing the multidimensional element entailed by inequality and paying special attention to the advances brought by studies of women in the sphere of capabilities. Section III moves from the theory to the measurement of capabilities. Section IV presents the data used to develop the model of analysis and construct the four capabilities that sum up a large amount of information on the situation of women in Chile; it also discusses the way these relate to the capabilities framework discussed earlier. Section V sets out the conclusions of the analysis in the light of the foregoing discussions. "justice as participatory parity". In the first case, people can be impeded from full participation because of the characteristics of economic structures that deny them the resources they need to interact with others as peers (distributive injustice). They may also be prevented from participating on equal terms because of the existence of institutionalized hierarchies of cultural value that deny them the appropriate status, in which case they are suffering from status inequality or misrecognition. The third dimension, which is the political one, concerns the jurisdiction of the State and the rules that organize political contestation. Politics, in this sense, provides the stage on which people's struggles for distribution and recognition are waged.

\section{The capability approach: from distributive justice to the philosophy of development}

A number of approaches have been developed to account for inequalities in the distribution of material and symbolic goods in societies. Among the most characteristic, mention should be made of Rawls (1971), an exponent of the classic conception of social justice which abstracts individuals from their environment, and Kymlicka (1991), who is closer to Sen in considering the influence of the cultural background of societies on the distribution of goods. Since 1980, Sen has offered a conceptual and methodological approach for dealing with the issue of development and inequalities, which he does by analysing the singularity of individuals and the radical differences between them when it comes to 
exercising the freedom to be and act and to gain access to the goods available in a society.

To understand how individuals can exercise their freedom, Sen distinguishes capability from functioning (Sen, 1977, 1979, 1985). Capability is the freedom individuals have to do or be, and to live a good life on the basis of their autonomous decisions and their own values: "Capability is thus a kind of freedom: the substantive freedom to achieve alternative functioning combinations (or, less formally put, the freedom to achieve various lifestyles)" (Sen, 2001, p. 75). The concept of capability refers to those "substantive freedoms" of individuals that allow them to develop whatever functions they believe to be of value. ${ }^{4}$ Functionings concern the degree to which people have been able to develop and exercise the capabilities considered essential to human development. Capabilities and functionings thus play a central role in determining individuals' levels of wellbeing and autonomy.

All in all, Sen's conception is an attempt to apprehend the singularity of each individual as a situated self, in his or her concrete circumstances, which means enriching the idea of equality with that of diversity and thereby counteracting the risks of standardization resulting from the abstraction of the idea of the "subject" or a homogenizing or excessively universalist view of human beings. Thus, for Sen, while two persons may have the same bundle of primary goods, they might have different freedoms to pursue their respective conceptions of what is good. Similarly, even if two individuals have the same income level, a great deal of inequality may subsist as regards their ability to achieve what they value. ${ }^{5}$

\section{The capability approach applied to the analysis of gender inequalities}

Gender is one of the fields where inequality is hardest to evaluate, for while there is abundant evidence, in both developed and developing countries, that women are worse placed than men in a number of dimensions, it is not easy to determine what the best indicator of this

\footnotetext{
${ }^{4}$ See Clark (2005) for a summary of critiques of the concept and its extended applications.

${ }^{5}$ For example, not all individuals will choose to apply their capabilities in the same way even if they have the same resources and capabilities, and will therefore not have the same functionings. The setting individuals live in and the limitations this imposes, and their own decisions - their capacity for agency, i.e., in Sen's language, the capacity of "someone who acts and brings about change, and whose achievements can be judged in terms of her own values and objectives" (Sen, 2001, p. 19)also bring major variations in the exercise of freedom.
}

inequality is. In Sen's approach, not all inequalities are negative, but some of their forms are damaging: "If those elements that do not derive from personal effort (gender, race, household origin) are the ones that account for inequality, then inequality is not acceptable. But if inequality is the result of people's effort, controlling for the other dimensions, then that inequality is acceptable" (Gamero Requena, 2006, p. 89). In this equation, gender is one of the variables that most seem to influence inequality of access to resources and the exercise of freedom, ranking among the unacceptable inequalities. A great many authors have taken up the challenge laid down by Sen (Anand, Hunter and Smith, 2005) and sought to produce a more or less fixed, more or less local or universalist list of capabilities that answer to the situations men and women actually experience. There is a great deal of debate about the validity of compiling such lists, since Sen himself has emphasized the need to be flexible and always to compile such lists for a specific context, place and space, thereby avoiding theoretical or a priori listings. Indeed, this very flexibility of Sen's contribution, and its degree of internal pluralism, are undoubtedly among the things that have allowed researchers to apply the theory productively.

On this basis, Nussbaum (1995, 2000, 2003 and 2005) and Robeyns (2003 and 2006) have drawn on Sen's theory to analyse differences in capabilities between men and women, thus building on the many efforts that have been made to complete, operationalize or specify the list of capabilities. Alert to the output of feminist theory, these authors have recognized that gender hierarchies, the private-public dichotomy and the inclusion and exclusion criteria of the structure of the rights that go to form citizenship have resulted in women being disadvantaged in public participation, in systems of political representation and in the possession of rights. They are confined primarily to the domestic world, where biological and social reproduction practices are also situated, and their experiences and problems are not usually considered proper subjects for collective decision-making, requiring mediation by the position of their partners (Goldthorpe, 1983). Thus, their prime responsibility for care tasks continually subjects them to the decisions and needs of others, diminishing their freedom. A social order structured around this sexual division of labour and representations of the female and the male deprives women of opportunities to develop their capabilities, something that is reflected in the different functionings of men's and women's capabilities.

One of the most thorough attempts to fix a universal list of capabilities is that undertaken by Nussbaum, who 
has drawn up a list of 10 separate but closely related components that ought to be assured if a person is to be able to exercise freedom and attain well-being: (i) life; (ii) physical health; (iii) physical wholeness; (iv) senses, imagination and thoughts; (v) emotions; (vi) practical reason; (vii) affiliation; (viii) relationship with other species; (ix) recreation; (x) political and material control over their own environment (Nussbaum, 1995, 2000, 2003 and 2005). In the context of the same discussion, Robeyns, also working on the basis of Sen's theory, proposes eight components for studying capabilities: (i) life and physical health; (ii) mental well-being, bodily integrity and safety; (iii) social relations; (iv) political empowerment; (v) education and knowledge; (vi) domestic work and non-market care; (vii) shelter and environment; (viii) mobility (Robeyns, 2003 and 2006). The contributions of these two authors are currently considered the most advanced in this field, but there is a fundamental difference between them. Nussbaum, true to the moral philosophy tradition, sought to draw up a list that could be valid in more than one context, while Robeyns has systematically sought to apply the list in accordance with the characteristics of specific countries, without seeking to "export" it to other situations.

\section{III}

\section{Capabilities and functionings: from theory to measurement}

A great deal has been written about the difficulties involved not only in defining capabilities in accordance with the type of analysis intended, but especially in measuring them. The empirical measurement of capabilities has been the subject of wide-ranging debate since the 1980s (Anand, Hunter and Smith, 2005), synthesized by the United Nations in the form of the human development index (HDI). Measurement has been carried out in a variety of countries by dint of adaptions and innovations in the measures (Martinetti, 2000). One of the cruxes of the debate is the data available, which are often secondary and thus somewhat removed from the original approach (Anand, Hunter and Smith, 2005; Robeyns, 2006). Furthermore, most of the empirical applications of the capability approach have been carried out in countries of the North, especially the United States and Europe (Alkire, 2002; Burchardt and Zaidi, 2003; Van Hees, 2004; Kuklys, 2005; Layte, Nolan and Whelan, 2000; Qizilbash, 1996; Schokkaert and Van Ootegem, 1990, among others). There have been few empirical applications or measurements of capabilities in countries of the South (Clark and Qizilbash, 2005, on South Africa) or in the developing countries (Majumdar and Subramanian, 2001, for India).

One of the greatest difficulties in empirical work, which has also been an issue for this study, is to distinguish between capabilities and functionings, since with real data this theoretical distinction becomes more tenuous (Anand, Hunter and Smith, 2005). With much of the data used in this field, including those used in this paper, both capabilities and functionings have been approached by means of questions, either about what people do (e.g., whether they vote or not, their education level) or about their opportunities (to continue studying, travel, etc.).

Setting out from Sen's capability concept, its adaptations to gender theory and the analysis of Fraser's four dimensions of gender injustice, this paper elaborates capabilities that are meant to be sensitive enough to capture the factors generating inequality between men and women and affecting women's freedom to develop their capabilities and bring about various improvements. Thus, four categories of capabilities are defined to compare men and women individually: material capability, social capability, cultural capability and political capability.

By the concept of material capability is meant here the individual ability to obtain resources autonomously and to use systems of social security to cope with situations of material vulnerability and risk resulting from ageing and health problems.

The concept of social capability refers to social resources that individuals can mobilize to increase their well-being (by accessing material and symbolic resources, for example) or deal with negative eventualities.

The concept of cultural capability alludes to the resources available to subjects to enable them to understand their environment and reflect critically on their lives and on society.

Lastly, political capability means people's ability to participate in and influence the political decisions that affect their own lives and the whole community. 
Thus defined, capabilities provide people with the resources they need to consolidate their material independence, develop a critical understanding of reality, build social trust and relationships and, lastly, participate in collective political and institutional decision-making. They are thus factors in the degrees of autonomy and security people have when it comes to taking decisions about their individual and collective welfare and anticipating situations of future vulnerability in four major areas of life.

\section{IV}

\section{Data, construction of tools and methods}

\section{The 2009 National Social Stratification Survey (enes)}

This study uses data from the National Social Stratification Survey (ENES) of the Desigualdades project to measure social mobility and stratification using both traditional variables and others that are not available from the instruments normally used to study social stratification in Chile, such as household surveys (National Socioeconomic Survey (CASEN)). ENES was applied between May and August $2009^{6}$ to a sample of 6,153 individuals $(3,141$ women) in 3,365 households. The sample is representative of the Chilean population aged 18 and over, ${ }^{7}$ as it has a random design with stratified (by region and zone) ${ }^{8}$ three-stage cluster sampling, involving the selection of blocks, households and individuals, with an estimated error for individuals nationally of $1.3 \%$, considering maximum variance and a confidence level of $95 \%$. In each household, sociodemographic information was obtained for the whole household and each of its members. Up to three household members over 18 were interviewed, including the main earner, the main earner's partner (if any) and another or other eligible subject(s) chosen at random. Interviews were conducted in person by a professional interviewer. The instrument comprises 12 modules that collect information on social and territorial identification, religion and travel, work, assets, education, social mobility, social capital, political position and participation, values, and personal and family situation. A subset of 5,443 ENES observations was used for this study, as individuals declaring themselves retired or disabled were not eligible for the analysis.

\footnotetext{
6 Survey conducted in the field by Statcom Estadísticos Consultores Ltda. 7 Universe of $11,965,900$ people as of June 2008, according to National Institute of Statistics (INE) population projections.

8 There are 45 strata: 15 regions and 3 zones (urban centres, other urban, rural). The design excludes Easter Island and Juan Fernández.
}

\section{Concepts and measurements}

On the basis of the empirical and theoretical material presented and a selection of variables included in ENES, indices were constructed to measure four specific capabilities: material capability, cultural capability, social capability and political capability. These indices combine a large amount of individual information, including conditions, practices or behaviours, and attitudes, making it possible to reduce the dimensionality of the problem and construct more parsimonious models. Their conceptual definition will now be summarized and details of their construction presented.

Returning first to the concept of "material capability", ${ }^{9}$ it should be recalled that this refers to individuals' ability ${ }^{10}$ to obtain resources autonomously and use systems of social security to cope with situations of material vulnerability and risk resulting from ageing and health problems. This is an important concept for those of working age not declaring themselves retired, a group represented by 5,443 observations in the sample and by the subset of observations that will be used in the analyses which follow. Material capability is measured by a three-category ordinal index distinguishing between individuals with low material capability $(32 \%)$, who are not employed and have no assets, ${ }^{11}$ those with medium

\footnotetext{
${ }^{9}$ To return to a point discussed earlier, material capability is the only measure which deals not with an attainment but with an outcome.

10 This is not to deny that there are people who acquire a substantial financial capital because of their household situation irrespective of their individual capabilities, as may happen in the case of a housewife married to someone with a high income. Thus, it is possible to obtain a substantial material capability without formal work or assets through a marital relationship, children or the extended family. However, the decision to work with individual capabilities focuses the analysis on what is obtained autonomously without transitivity vis-à-vis other people and can therefore withstand changes in a person's family situation or ties to others.

${ }^{11}$ Such as a partnership in a business, ownership of rental properties, cattle, machinery, etc.
} 
material capability (29\%), who have a job or asset but no social security, ${ }^{12}$ and those with high material capability (39\%), who have a job or assets and social security as well. It should be emphasized that this measurement is independent of the household's income level or living standards. Thus, two people with different incomes may fall into the same material capability category, as will be seen further on. The advantage of this for the purposes of the present study is that it can be used to describe women's material autonomy, irrespective of their employment position and of the living standards of the household they belong to, thus helping to resolve one of the problems in measuring inequality as it affects women.

The concept of "cultural capability", in turn, refers to the resources subjects have available to them for understanding their environment and reflecting critically on their lives. It is measured by an index that combines, first, the years of education and knowledge of a foreign language dimensions (low, medium and high), with a weighting of 0.3 apiece in the overall scale, and second, the frequency of travel abroad and the number of courses undertaken outside of formal education or for training purposes, with these dimensions having a weighting of 0.2 apiece.

The concept of "social capability" refers to social resources individuals can mobilize to increase their wellbeing (e.g., access to material and symbolic resources) or to cope with negative eventualities, as shown by network theory (Granovetter, 1973; Porras and Espinoza, 2005). It is measured by an index that combines: the diversity of personal networks, given by the number of acquaintances an individual reports from a set of 12 different occupations; associative participation, given by active participation in at least one association; and two attitudes: community engagement and interpersonal

12 For present purposes, having social security means paying into a pension system and having access to a health system. trust, variables that are latent or not directly observable and that consequently require special treatment. ${ }^{13}$

What is considered for the "political capability" concept, lastly, is people's ability to participate in and influence the political decisions affecting their lives. This is measured by an index combining: registration on the electoral roll declared by the respondent; level of political knowledge, given by the number of correct answers to basic questions about politics; ${ }^{14}$ and attitudes: trust in political institutions, tendency to discuss and seek information about politics and willingness to engage in political activities, the measures for which were constructed by the same method as was used for the latent variables of the social capability index.

Table 1 shows the descriptive statistics ${ }^{15}$ for the capability measures constructed.

\footnotetext{
13 These attitudes were measured using scales defined by exploratory factor analysis (FA), i.e., with groups of items that were clearly allocated by a theoretically interpretable factor. For this model, use was made of a set of 10 items whose purpose was to ascertain the frequency of activities carried out for the benefit of the community and the degree of trust in different people, all with quasi-metric response scales. To obtain this measurement model, AF with principal components extraction and oblique rotation (oblimn) was used, on the theoretical assumption that all the resulting factors ought to be correlated. In addition, mean imputation was carried out for items with missing information to minimize sample loss by list. A solution was obtained with two factors that could be interpreted as community engagement and trust, respectively. The community engagement scale grouped six items with factor weights of between 0.60 and 0.75 and presented a Cronbach's alpha of 0.75 , indicating that the scale had an adequate level of internal consistency or reliability. The interpersonal trust scale grouped four items with factor weights of between 0.67 and 0.85 and had a Cronbach's alpha of 0.79 . The regression method was then used to obtain factor scores assigning a summary measure of each attitude to each observation on a continuous scale. To construct the final social capability measure, its four dimensions were combined with equal weightings (i.e., 0.25 each) into an index theoretically ranging from 0 to 100 . This index presents a mean of 29 points with a standard deviation of 17 , for 5,443 valid observations.

${ }^{14}$ Specifically: correctly identifying the election mechanism for the regional government and governors, and identifying the names of authorities (mayor, governor and interior minister).

15 Sample weighting (standard expansion factor) has been used in all calculations to ensure that the statistics are representative of the universe studied.
}

Descriptive statistics for the capability measures

\begin{tabular}{lccccc}
\hline & Number of observations & Minimum & Maximum & Mean & Standard deviation \\
\hline Cultural capability & 5428 & 0 & 79.43 & 21.08 & 13.54 \\
Political capability & 5443 & 2.31 & 94.5 & 32.75 & 14.98 \\
Social capability & 5209 & 0.65 & 97.23 & 28.7 & 16.85 \\
\hline
\end{tabular}

Source: National Social Stratification Survey (ENES), 2009. 


\section{Models and control variables}

To ascertain the effect of sex on the capability measures constructed, use was made of analytical techniques appropriate to their measurement levels, with adjustments in successive models that took each of the capabilities as dependent variables.

A multicategory logit model was used to study the relationship of sex to material capability; what was estimated in this case was the relationship between the likelihood of response of an ordinal dependent variable and a set of categorical and continuous explanatory variables. The response variable was the logarithm of the odds of an alternative in relation to a reference category. The exponent of the additive parameters of the model predictors was taken to obtain multiplicative parameters, which can be interpreted as the geometrical mean of the increase $\left(\beta_{\mathrm{i}}>1\right)$ or decrease $\left(\beta_{\mathrm{i}}<1\right)$ in the odds of a category of the dependent variable in relation to the reference category (for example, odds of material capability below the mean), controlling for all the other model factors. The further these parameters are from 1 , the stronger the effects (with 0 as the lower limit), while parameters close to 1 indicate an absence of effect (Billiet, 1995). Because the response variable has three categories for each continuous predictor, two parameters are estimated, and for each categorical predictor twice the number of categories minus 1 .

The relationship between sex and cultural, social and political capability was studied with three respective models. The technique used was linear regression (ordinary least squares). In this type of model, the parameters ( $\beta$ in tables 6, 7 and 8 below) are interpreted as the change in outcome (capability in this case) related to a change of one unit in a predictor, controlling for all the other model factors. When a predictor is categorical, its parameter is interpreted as a change in the outcome associated with a category by contrast with a reference category. The standardized $\beta$ 's can be used to compare the size of the effect across independent variables. In this case, possible interactions between sex and other predictors were tested using a method of reverse elimination of effects.

Together with sex, included as the dummy variable female $(51.4 \%)$, the following were included as independent variables in the adjusted models (both logit and regression) on the basis of theoretical considerations: age last birthday; children $<18,{ }^{16}$ indicating whether the respondent has children who are minors (51.1\%); rural, indicating whether the respondent lives in a rural area (13.1\%); socioeconomic level, which is the household's score based on the availability of goods and education level of the main earner, ${ }^{17}$ indicative of living standards. To explain each specific capability, furthermore, all the other capabilities were included as predictors. This made it possible to determine the net effect of sex on each capability, controlling for a set of sociodemographic variables and other capabilities assumed to be relevant. Table 2 summarizes the statistics of these variables.

\footnotetext{
16 The fact of having children under 18 is important, as one of the fundamental hypotheses of studies in the field is that this particularly affects women's capabilities and autonomy.

${ }^{17}$ According to the matrix of the International Marketing Association (IMA).
}

Summary statistics for the variables used

\begin{tabular}{lcrrrr}
\hline & Number of observations & Mean & Standard deviation & Minimum & Maximum \\
\hline Female & 5443 & 0.51 & 0.50 & 0 & 1 \\
Q84: Age last birthday & 5443 & 39.51 & 14.45 & 18 & 93 \\
Children < 18 & 5443 & 0.51 & 0.50 & 0 & 1 \\
Socioeconomic level 2008 (score) & 5230 & 354.02 & 243.76 & 0 & 1000 \\
Rural & 5443 & 0.13 & 0.34 & 0 & 1 \\
\hline
\end{tabular}

Source: National Social Stratification Survey (ENES), 2009. 


\section{V}

\section{Findings}

\section{Differences observed}

A straightforward review of the sex differences observed in the capability measures constructed suggests that women are in a situation of disadvantage in every one of them. To start with, women evince a significantly lesser

TABLE 3

Material capability, by gender

(Percentages)

\begin{tabular}{lccc}
\hline $\begin{array}{l}\text { Material } \\
\text { capability }\end{array}$ & Male & Female & $\begin{array}{c}\text { Number of } \\
\text { observations }\end{array}$ \\
\hline Low & 18.3 & 45.3 & 1750 \\
Medium & 28.9 & 28.2 & 1552 \\
High & 52.8 & 26.5 & 2137 \\
Total & 100.0 & 100.0 & 5439
\end{tabular}

Source: National Social Stratification Survey (ENES), 2009.

$\chi^{2}=545.52 ; \mathrm{df}=2, * \mathrm{p}<0.000 ;$ Gamma $=-0.49$. material capability than men. In this case, the size of the sex effect as measured by the Gamma statistic can be considered large, as indicated in table 3 .

Secondly, as indicated below, the cultural, social and political capability of women is observed to be significantly lower than men's on average; the size of the effect is small, however.

There will now be an analysis of the extent to which these observed differences are maintained when the sex-capabilities relationship is modelled, controlling for a number of factors that are assumed to be relevant. In adjusting these models (logit and linear regressions), the calculation of standard errors associated with the parameters of the predictors took account of the stratified cluster sample design used to select ENES participants.

\section{Net effects}

Table 5 presents the material capability model.

TABLE 4

Differences between men and women in average cultural, social and political capabilities ${ }^{a}$

\begin{tabular}{lcccccc}
\hline & Male average & $\begin{array}{c}\text { Female } \\
\text { average }\end{array}$ & t-statistic & $\begin{array}{c}\text { Degrees of } \\
\text { freedom }(\mathrm{df})\end{array}$ & $\begin{array}{c}\text { Significance } \\
\text { (bilateral) }\end{array}$ & $\begin{array}{c}\text { Pearson's correlation } \\
\text { coefficient }(r)\end{array}$ \\
\hline Cultural capability $^{\mathrm{b}}$ & 23.9 & 20.4 & 9.32 & 4814.9 & 0.00 & 0.13 \\
Social capability $^{\mathrm{b}}$ & 30.4 & 27.1 & 7.45 & 5371.2 & 0.00 & 0.10 \\
Political capability $^{\mathrm{b}}$ & 33.8 & 31.7 & 5.10 & 5338.0 & 0.00 & 0.07 \\
\hline
\end{tabular}

Source: National Social Stratification Survey (ENES), 2009.

a Equality of variance is not assumed.

b Does not meet the normality assumption. The non-parametric test yielded similar results.

TABLE 5

Material capability model

(Multiplicative parameters)

\begin{tabular}{lccr}
\hline Predictor & $\begin{array}{c}\text { Below average } \\
\text { capability }\end{array}$ & $\begin{array}{c}\text { Above average } \\
\text { capability }\end{array}$ & $\begin{array}{c}\text { Chi-square } \\
\text { (degrees of freedom) }\end{array}$ \\
\hline (Constant) & 0.710 & $2.347^{* *}$ & $72.15^{* *}(2)$ \\
Female (reference: male) & $2.851^{* * *}$ & $0.524^{* * *}$ & $510.82^{* *}(2)$ \\
Age in years & $0.986^{* *}$ & 0.991 & $21.24^{* *(2)}(2)$ \\
Children < 18 (reference: none) & $0.545^{* * *}$ & 1.260 & $124.04^{* *}(2)$ \\
Socioeconomic level & 1.000 & $1.001^{* * *}$ & $46.23^{* *}(2)$ \\
Rural area (reference: urban area) & 1.034 & 0.682 & $15.60^{* *(2)}(2)$ \\
Cultural capability & 0.988 & $1.012^{*}$ & $36.65^{* * *}(2)$ \\
Social capability & $0.985^{* *}$ & $0.990^{* *}$ & $38.17^{* *(2)}$ \\
Political capability & 0.996 & $1.010^{* *}$ & $20.87^{* *}(2)$ \\
\hline
\end{tabular}

Source: National Social Stratification Survey (ENES), 2009.

Cox and Snell's pseudo $\mathrm{R}^{2}=0.188$, Nagelkerke's pseudo $\mathrm{R}^{2}=0.212 ; * * * \mathrm{p}<0.001$, ** $\mathrm{p}<0.01$, $\mathrm{p}<0.05$. 
These findings reveal that the female variable presents the greatest correlation even after controlling for the effects of the other variables. The effect is significant, operates in the expected direction (i.e., to women's disadvantage) and can be considered moderate. According to the parameters, women are on average three times as likely as men to be in the low material capability category as opposed to the medium one, and half as likely to belong to the high material capability category as opposed to the medium one. Having children under 18 is the second most important variable in the model. This situation almost doubles the likelihood (1/0.55) of having medium versus low material capability, while living in a rural area reduces by a third the likelihood of having high as opposed to medium capability (1/0.68). The remaining predictors, particularly socioeconomic level and other capabilities, present weak relationships with material capability, i.e., the parameters are very close to 1 , although they are statistically significant on occasion. ${ }^{18}$

Table 6 presents the cultural capability model.

In the cultural capability model, it is observed that when the other variables are controlled for, the fact of being female reduces cultural capability by an average of 0.7 points; however, this parameter is not statistically significant $(p=0.23)$. In this model, the

18 This happens when a high value is obtained for the Wald statistic used to test the contribution of each predictor. That statistic is calculated as the square of the ratio between the additive parameter of each predictor and its standard error, on the assumption that it follows a chi-square distribution (Garson, 2011). most important of the explanatory variables significantly related to cultural capability prove to be socioeconomic level, with a positive correlation, age, which presents a non-linear negative relationship, and social capability, with a positive association. No evidence was found for major interactions between the fact of being female and other predictors.

Table 7 shows the social capability model.

Here it is observed that when the rest of the explanatory variables are controlled for, women's social capability is just over a point lower, but as in the previous case this effect is not statistically significant $(\mathrm{p}=0.18)$. In this model, the most important effects are those of cultural and political capabilities, as the standardized coefficients suggest. Again, no evidence was found of major interactions between the fact of being female and other predictors.

Table 8 presents the political capability model.

In this model, by contrast with what was seen in the explanation for cultural and social capabilities, being female has a negative and statistically significant effect $(p=0.023)$, i.e., on average women score over a point less than men on the political capability index. When the standardized coefficients are compared, it is seen that age is the most important predictor in this model, followed by socioeconomic level and social capability. Confirming previous observations, no significant interactions were found between sex and other explanatory variables.

To sum up, this exercise has partially confirmed the hypotheses of the present study about the relationship between gender and capabilities. The relationship between being female and a lesser material capability is shown to

TABLE 6

Cultural capability model

\begin{tabular}{lccc}
\hline Predictor & $\beta$ & Linearized standard error & Standardized $\beta$ \\
\hline (Constant) & 22.73 & 0.83 & -0.02 \\
Female (reference: male) & -0.68 & 0.56 & $-0.26^{* * *}$ \\
Age in years & -0.25 & 0.02 & $0.05^{*}$ \\
Age & 0.00 & 0.00 & -0.05 \\
Children < 18 (reference: none) & -1.24 & 0.69 & $0.49^{* * *}$ \\
Socioeconomic level & 0.03 & 0.00 & $-0.04^{* *}$ \\
Rural area (reference: urban area) & -1.47 & 0.56 & $0.18^{* * *}$ \\
Social capability & 0.15 & 0.02 & $0.08^{* *}$ \\
Political capability & 0.07 & 0.02 & -0.03 \\
Low material capability & -0.81 & 0.56 & $0.05^{*}$ \\
High material capability & 1.51 & 0.61 & \\
(Reference: medium material capability) & 22.73 & & \\
\hline
\end{tabular}

Source: National Social Stratification Survey (ENES), 2009.

$\mathrm{R}^{2}=0.46 ; * * * \mathrm{p}<0.001, * * \mathrm{p}<0.01,{ }^{*} \mathrm{p}<0.05$. 
TABLE 7

Social capability model

\begin{tabular}{|c|c|c|c|}
\hline Predictor & $\beta$ & Linearized standard error & Standardized $\beta$ \\
\hline (Constant) & 31.28 & 1.06 & \\
\hline Female (reference: male) & -1.18 & 0.88 & -0.04 \\
\hline Age in years & -0.05 & 0.04 & -0.05 \\
\hline Children < 18 (reference: none) & -1.13 & 0.85 & -0.03 \\
\hline Socioeconomic level & 0.01 & 0.00 & $0.09 * *$ \\
\hline Rural area (reference: urban area) & 3.70 & 2.03 & 0.07 \\
\hline Cultural capability & 0.33 & 0.04 & $0.27 * * *$ \\
\hline Political capability & 0.25 & 0.04 & $0.22 * * *$ \\
\hline Low material capability & -3.51 & 1.00 & $-0.10 * * *$ \\
\hline High material capability (reference: medium material capability) & -2.45 & 0.94 & $-0.07 * *$ \\
\hline
\end{tabular}

Source: National Social Stratification Survey (ENES), 2009.

$\mathrm{R}^{2}=0.19 ; * * * \mathrm{p}<0.001, * * \mathrm{p}<0.01, * \mathrm{p}<0.05$

TABLE 8

\section{Political capability model}

\begin{tabular}{|c|c|c|c|}
\hline Predictors & $\beta$ & Linearized standard error & Standardized $\beta$ \\
\hline (Constant) & 34.98 & 0.95 & \\
\hline Female (reference: male) & -1.40 & 0.61 & $-0.05^{*}$ \\
\hline Age $^{2}$ & -0.01 & 0.00 & $-0.19 * * *$ \\
\hline Children $<18$ (reference: none) & -0.01 & 0.68 & 0.00 \\
\hline Socioeconomic level & 0.01 & 0.00 & $0.17 * * *$ \\
\hline Cultural capability & 0.10 & 0.04 & $0.09 * *$ \\
\hline Social capability & 0.16 & 0.03 & $0.17 * * *$ \\
\hline Low material capability & 0.36 & 0.89 & 0.01 \\
\hline High material capability & 1.17 & 0.89 & 0.04 \\
\hline (Reference: medium material capability) & 34.98 & & \\
\hline
\end{tabular}

Source: National Social Stratification Survey (ENES), 2009.

$\mathrm{R}^{2}=0.38 ; * * * \mathrm{p}<0.001, * * \mathrm{p}<0.01, * \mathrm{p}<0.05$.

be an important effect even after controlling for significant sociodemographic variables and other capabilities. When this exercise is repeated with cultural and social capability, the correlation observed initially, while it retains its direction, tends to zero and is not statistically significant. Again, the negative effect of being female on political capability is reduced substantially when controls such as age, socioeconomic level, household characteristics and other capabilities are introduced into the model; nonetheless, it remains statistically significant. Thus, there is evidence for a net effect of sex on these capabilities to women's detriment, but it is weak compared to the magnitude of the significant parameters of variables such as age, household socioeconomic level and social and cultural capabilities. Lastly, and against expectations, no evidence was found of interactions between sex and other predictors of capabilities, i.e., the functioning of the explanatory variables studied is apparently stable between men and women.

\section{Discussion and conclusions}

The findings bear out the core hypothesis of this study that women's capabilities are less developed than men's in the case of material and political capabilities, while the relationship between gender and cultural and social capabilities, although operating in the expected direction, is not sufficiently strong. These capabilities were measured using indices especially developed from the variables in the 2009 National Social Stratification Survey (ENES), which were applied within the framework of the Desigualdades project. Each of the indices combined a large amount of individual information, including conditions, practices or behaviours, and attitudes, and this made it possible to 
produce a more complex picture of the way differences between women and men are expressed, while at the same time reducing the dimensionality of the problem by constructing more parsimonious models.

Women evince a significantly lower material capability than men, which, by definition, means a lesser ability to obtain resources autonomously and use systems of social security to deal with situations of material vulnerability and risk deriving from ageing and health problems. The relationship between being female and material capability proves important even after controlling for major independent variables and the influence of other capabilities. These findings, which show women to be overrepresented in the low and medium material capability categories, reveal the structuring role of the gender relationship entailed in the sexual division of labour, which assigns women almost exclusive responsibility for domestic and unpaid care work and men the responsibility of providing for the household. This places women in a situation of dependence on the incomes and probably the choices of others.

In the explanatory models for social, cultural and political capability, female disadvantage persists after controlling for a set of explanatory variables, albeit exceptionally to a significant degree, in sharp contrast with women's much lower material capability. There are possible explanations for this: measurement of material capability refers to women's and men's potential for autonomy irrespective of the functionings attained, by contrast with the situation for the other capabilities, where it was harder to differentiate capabilities from functionings. This finding also makes sense from the viewpoint of gender theory, which postulates that the separation of private and public spaces and the sexual division of labour constitute the structural basis of the gender order and are particularly stable and resistant to changes over time, such as the greater access to education and public spaces that women now enjoy.

The weak correlation between the fact of being female and cultural capability is consistent with the findings of the studies by ECLAC, the Women's Studies Centre and the National Institute of Statistics (INE), which are at one in showing that sex divides have narrowed most significantly in the field of education over the past 20 years. In fact, women entering the labour market now have higher levels of education than men.

Measures of social capability - social resources that individuals can mobilize to increase their well-being or cope with negative eventualities - indicate a very slight disadvantage for women as compared with men. This finding could be due to the survey encompassing the forms of social life found in both rural and urban areas: community networks are more stable in the former, while in the case of the latter the most recent Human Development Report for Chile dealing with gender issues (UNDP, 2010) showed that women had expanded their social networks over the past 20 years as a result of individuation processes associated with the country's modernization.

It is interesting that political capability is the other capability for which women are at a significant disadvantage. Just as the sexual division of labour and the separation of production spheres account for women's lesser material capability, cultural representations of men's and women's capabilities and fields of action and the coexistence of a twofold political and family authority over women reveal the cultural roots underlying this difference. Representations assign the spheres of politics and national decision-making to men and spheres of a more social or family character to women. These representations are interiorized and shape men's and women's motivations and expectations in the field of politics. At the same time, from an institutional perspective, a number of studies have revealed the mechanisms used to discourage women from participating in politics. In short, the results taken together show how the development of capabilities is the outcome of complex systemic processes relating to women's and men's positions within the social relationships that configure the gender order. Some of the positions occupied by women and men are resistant to change, as they constitute the structural bases of the gender order; others are more subject to the effect of different variables and ongoing social transformation processes, such as modernization and the individuation processes associated with it.

(Original: Spanish) 


\section{Bibliography}

Acosta, E., M. Perticará and C. Ramos (2005), Oferta laboral femenina y cuidado infantil, Washington, D.C., Inter-American Development Bank (IDB).

Alkire, S. (2002), "Dimensions of human development", World Development, vol. 30, No. 2, Amsterdam, Elsevier.

Altman, D. (2004), "Redibujando el mapa electoral chileno: incidencia de factores socioeconómicos y género en las urnas", Revista de ciencia política, vol. 24, No. 2, Santiago, Chile, Catholic University of Chile.

Anand, P., G. Hunter and R. Smith (2005), "Capabilities and wellbeing: Evidence based on the Sen-Nussbaum approach to welfare", Social Indicators Research, vol. 74, No. 1, New York, Springer.

Astelarra, J. (2003), ¿Libres e iguales? Sociedad y política desde el feminismo, Santiago, Chile, Centre for Women's Studies (CEM).

Berstein, S. and A. Tokman (2005), "Brechas de ingreso entre hombres y mujeres: ¿Perpetuadas o exacerbadas en la vejez?”, Working Papers, No. 334, Santiago, Chile, Central Bank of Chile.

Bertranou, F. (2005), "Pensions and gender in Latin American social protection systems: Where do we stand in the Southern Cone?", paper prepared for the issa Expert Group Meeting on Gender, Retirement, and Active Aging: Implications for Social Security in Long-life Societies, Geneva, International Labour Organization, June.

Bertranou, F. and A. Arenas (eds.) (2003), Protección social, pensiones y género, Santiago, Chile, International Labour Organization.

Bihr, A. and R. Pfefferkorn, (2008), Le système des inégalités, Paris, La Découverte.

Billiet, J.B. (1995), "Church involvement, ethnocentrism, and voting for a radical right-wing party: Diverging behavioral outcomes of equal attitudinal dispositions", Sociology of Religion, vol. 53, No. 3, New York, Oxford University Press.

Burchardt, T. and A. Zaidi (2003), "Comparing incomes when needs differ: Equivalisation for the extra costs of disability in the UK", lse Case Paper, No. 64, London, London School of Economics.

Clark, D.A. (2005), "The capability approach: Its development, critiques and recent advances", Working Paper, No. 32, Manchester, Global Poverty Research Group.

Clark, D.A. and M. Qizilbash (2005), "Core poverty, basic capabilities and vagueness: An application to the South African context", Working Paper, No. 26, Manchester, Global Poverty Research Group.

Contreras, M.E. (2004), Educación y género. Un desafío a la organización magisterial, Santiago, Chile, Colegio de Profesores de Chile/National Women's Service (SERNAM).

Contreras, D. and G. Plaza (2010), "Cultural factors in women's labor force participation in Chile", Feminist Economics, vol. 16, No. 2, New York, Routledge.

Contreras, D., E. Puentes and D. Bravo (2005), "Female labour force participation in greater Santiago, Chile: 1957-1997. A synthetic cohort analysis", Journal of International Development, vol. 17, No. 2, Mansfield, University of Connecticut.

Dussaillant, F. (2009), “Más salas cunas o permisos post natales más largos? Una comparación de alternativas de política para apoyar a la maternidad y a la primera infancia”, Documento de trabajo, No. 377, Santiago, Chile, Centre for Public Studies (CEP), May.

Fraser, N. (1989), Unruly Practices: Power, Discourse, and Gender in Contemporary Social Theory, Minneapolis, Minnesota, University of Minnesota Press.

(1985), "What's critical about critical theory? The case of Habermas and gender", New German Critique, No. 35, Durham, North Carolina, Duke University Press.
Fraser, N. and others (1994), Feminist Contentions: A Philosophical Exchange, London, Routledge.

Gamero Requena, J. (2006), "Políticas sociales post-keynesianas. Después del ajuste: ¿qué modelo?", Confrontaciones monetarias: marxistas y post-keynesianos en América Latina, A. Girón, Buenos Aires, Latin American Social Sciences Council (CLACSO).

Garson, D. (2011), "Binary and Multinomial Logistic Regression" [online] http://faculty.chass.ncsu.edu/garson/PA765/logistic. htm.

Goldthorpe, J. (1983), "Women and class analysis: In defence of the conventional view", Sociology, vol. 17, No. 4, Thousand Oaks, Sage.

Granovetter, M. (1995), Getting a Job: A Study of Contacts and Careers, Chicago, University of Chicago Press.

(1973), "The strength of weak ties", American Journal of Sociology, vol. 78, No. 6, Chicago, University of Chicago Press.

Guerrero, E., P. Provoste and A. Valdés (2006a), "Acceso a la educación y socialización de género en un contexto de reformas educativas", Equidad de género y reformas educativas. Argentina, Chile, Colombia, Perú, Patricia Provoste (ed.), Santiago, Chile, Hexagrama Consultoras.

(2006b), "La desigualdad olvidada: Género y educación en Chile", Equidad de género y reformas educativas. Argentina, Chile, Colombia, Perú, Patricia Provoste (ed.), Santiago, Chile, Hexagrama Consultoras.

Guzmán, V. and A. Mauro (2004), "Las trayectorias laborales de mujeres de tres generaciones: Coacción y autonomía", El trabajo se transforma. Relaciones de producción y relaciones de género, R. Todaro and S. Yáñez (eds.), Santiago, Chile, Andros.

Kuklys, W. (2005), Amartya Sen's Capability Approach: Theoretical Insights and Empirical Applications (Studies in Choice and Welfare), Berlin, Springer-Verlag.

Kymlicka, W. (1991), Contemporary Political Philosophy. An Introduction, New York, Oxford University Press.

Larrañaga, O. (2001), "Distribución de ingresos en Chile: 19582001", Documento de trabajo, No. 178, Santiago, Chile, Department of Economics, University of Chile.

Layte, R., B. Nolan and C. Whelan (2000), "Targeting poverty: Lessons from monitoring Ireland's national anti-poverty strategy", Journal of Social Policy, vol. 29, No. 4, Cambridge, Cambridge University Press.

Le Foulon, C. and H. Beyer (2002), "Un recorrido por las desigualdades salariales en Chile", Estudios públicos, vol. 85, Santiago, Chile, Centre for Public Studies (CEP).

Leiva, S. (2000), "El trabajo a tiempo parcial en Chile. ¿Constituye empleo precario? Reflexiones desde la perspectiva de género", Mujer y desarrollo series, No. 26 (LC/L.1301-P), Santiago, Chile, Economic Commission for Latin America and the Caribbean (ECLAC). United Nations publication, Sales No. S.00.II.G.09.

Lombardo, E. (2008), "Gender inequality in politics", International Feminist Journal of Politics, vol. 10, No. 1, New York, Routledge.

Majumdar, M. and S. Subramanian (2001), "Capability failure and group disparities: Some evidence from India for the 1980s", Journal of Development Studies, vol. 37, No. 5, New York, Routledge.

Martinetti, E. (2000), "A multidimensional assessment of well-being based on Sen's functioning approach", Rivista internazionale di scienze sociali, vol. 108, No. 2, Rome, Università Cattolica del Sacro Cuore.

MINEDUC (Ministry of Education) (2007), "Indicadores de la educación en Chile 2007”, preliminary paper, Santiago, Chile. 
(s/f), "Indicadores de la educación en Chile 2006", Santiago, Chile.

Nussbaum, M. (2005), "Well-being, contracts and capabilities", Rethinking Well-Being, L. Manderson (ed.), Perth, API Network. (2003), "Capabilities as fundamental entitlement: Sen and social justice", Feminist Economics, vol. 9, No. 2-3, New York, Routledge.

(2000), Women and Human Development: the Capabilities Approach, Cambridge, Cambridge University Press.

(1995), "Human capabilities, female human beings", Women, Culture and Development, M. Nussbaum and J. Glover (eds.), Oxford, Clarendon Press.

Osborne, R. (2005), "Desigualdad y relaciones de género en las organizaciones: diferencias numéricas, acción positiva y paridad", Política y sociedad, vol. 42, No. 2, Madrid, Universidad Complutense de Madrid.

Perticará, M. and I. Bueno (2009), "A new approach to gender wage gaps in Chile", cepal Review, No. 99 (LC/G.2418-P), Santiago, Chile.

Porras, J.I. and V. Espinoza (2005), Redes. Enfoques y aplicaciones del análisis de redes sociales (ars), Santiago, Chile, Universidad Bolivariana.

Qizilbash, M. (1996), "Capabilities, wellbeing and human development", Journal of Development Studies, vol. 36, New York, Routledge.

Rawls, J. (1971), A Theory of Justice, Cambridge, Harvard University Press.

Ríos, M. (2008), Mujer y política. El impacto de las cuotas de género en América Latina, Santiago, Chile, Catalonia.

Robeyns, I. (2006), "Measuring gender inequality in functionings and capabilities. Findings from the British household panel survey",
Gender Disparity: Manifestations, Causes and Implications, P. Bharati and M. Pal (comps.), New Delhi, Anmol Publishers. (2003), "Sen's capability approach and gender inequality: Selecting relevant capabilities", Feminist Economics, vol. 9, No. 2-3, New York, Routledge.

Schokkaert, E. and L. Van Ootegem (1990), "Sen's concept of the living standard applied to the Belgium unemployed", Recherches économiques de Louvain, vol. 56, Louvain, Catholic University of Louvain.

Sen, A. (1999), Development as Freedom, Oxford, Oxford University Press.

(1985), Commodities and Capabilities, Amsterdam, NorthHolland Press.

(1979), "Personal utilities and public judgments: Or what's wrong with welfare economics?", Economic Journal, vol. 89, Hoboken, Wiley-Blackwell.

(1977), "Social choice theory: A re-examination", Econometrica, vol. 45, No. 1, New York, The Econometric Society.

Todaro, R. and S. Yáñez (2004), El trabajo se transforma. Relaciones de producción y relaciones de género, Santiago, Chile, Centre for Women's Studies (CEM).

UNDP (United Nations Development Programme) (2010), Género: Los desafíos de la igualdad, Santiago, Chile.

Valcárcel, A. (1991), Sexo y filosofía: sobre mujer y poder, Madrid, Anthropos Editorial.

Valdés, T. (2000), De lo social a lo político. La acción de las mujeres latinoamericanas, Santiago, Chile, Lom Ediciones.

Van Hees, M. (2004), "Freedom of choice and diversity of options: Some difficulties", Social Choice and Welfare, vol. 22, No. 1, Amsterdam, Elsevier. 